\title{
Isolation and Identification of Indole Acetic Acid (IAA) Producing Bacteria from Organic Soil: Investigating Its Efficacy on Plant Growth
}

\author{
Yamini $\mathbf{P}^{1}$, Reshmi Gopalakrishnan ${ }^{1}$, Sanjay Prasad $S^{2 *}$, Karkuvelraja $\mathbf{R}^{3}$
}

\author{
Author details \\ ${ }^{1}$ Department of Microbiology, Sri Ramakrishna College of Arts and Science for Women, \\ Coimbatore, TamilNadu-641044, India \\ ${ }^{2}$ Department of Microbiology, Department of Microbiology, CMS College of Science and \\ Commerce, Coimbatore-641049, TamilNadu, India. (*Corresponding author) \\ ${ }^{3}$ Microbial Biodiversity and Bioenergy Lab, Department of Microbiology, Bharathidasan \\ University, Tiruchirapalli-620024, India
}




\begin{abstract}
:
Indole acetic acid (IAA) production is a major property of rhizosphere bacteria that stimulate and facilitate plant growth. The present work deals with isolation, characterization and identification of indole acetic acid producing bacteria from the rhizospheric soil. Out of four organisms isolated from serial dilution, Sample-2 confirmed thick bands of IAA production by TLC analysis. 16s rRNA analysis showed the isolated organism was found to be Pseudomonas fluorescence with similarity of $88 \%$. The isolated organism treat plants showed increased shoot and root length in plant growth analysis.In conclusion the isolated IAA producing bacteria can be used as efficient biofertilizer inoculants to promote plant growth.
\end{abstract}

KEYWORDS: Tryptophan, rhizobacteria, purification, optimization, plant nutrition 


\section{INTRODUCTION:}

Biofertilizers are one of the excellent tool for sustainable agriculture. Biofertilizers improves soil fertility through solving atmospheric nitrogen, each, in affiliation with plant roots and with out it, solubilize insoluble soil phosphates minerals and produces plant boom materials with inside the soil.Biofertilizer incorporates microorganisms which provides good enough deliver of vitamins to the host flora and make sure their right improvement of growth and law of their physiology. Effective dwelling microorganisms are used in the instruction of biofertilizers. (Sadaf Shahab et al,2009).

The common production of plant growth regulators are (auxin, gibberellin,ethylene etc.), siderophores, HCN and antibiotics (Arshad and Frankenberger, 1992). Indole acetic acid is an crucial (IAA)physiologically lively auxins. IAA is commonly made from L-tryptophan metabolism via way of means of numerous microorganisms consisting of PGPR(Shahab $S$ et al,2008).Microorganisms inhabiting rhizospheres of numerous plant life are in all likelihood to synthesize and launch auxin as secondary metabolites due to the rich elements of substrates exuded from the roots as compared with non rhizospheric soils (Kampert et al., 1975). Plant growth promoting rhizobacteria (PGPR) is a micro organism that actively colonize plant roots and has a more yield and greater growth.

One of the alternative maximum crucial powerful elements in growing plant yield is seed inoculation or priming with plant growth promoting rhizobacteria (PGPR). Also, plant growth promoting rhizobacteria (PGPR) are a collection of micro organism that actively colonize plant roots and growth plant increase and yield (Subba RaO 1999; Wu et al., 2005; Heidari et al.,2011). Some chemical fertilizers in use incorporate poisonous through-additives inclusive of heavy metals, inorganic acids and natural pollutants, and hence, a long-time period utility of those chemical fertilizers can probable set off the buildup of those with the aid of using-additives in soil, leading to the worsening of soil ecological environment, and making the heavy metals, nitrate, and different dangerous additives in agricultural merchandise consisting of greens, grains and culmination critically passed the standards(Verma J.P et al., (2014)).

Increasing agricultural productiveness is presently related to the sizeable software of chemical fertilizers.However, issues like better cost, pollutants of herbal assets and fitness implications have forced researches to discover options for secure and expanded crop 
productiveness. One such opportunity is using PGPB, especially IAA generating microorganism.Beneficial microbial allelopathies in rhizosphere are a key agent of alternate in soil environment and have an effect on crop fitness and yield (Sturz and Christie, 2003). Due to such precious attribute, isolation of indigenous bacterial lines with plant boom selling capacity from diverse environments stays a famous concept. In this regard, the existing observe turned into performed to isolate capacity IAA producing micro organism .

Indole acetic acid (IAA) directs numerous factors of plant growth and development,including the induction and regulation of a variety of processes: e.g., Cellular department, root extension, vascularization, apical dominance, and tropisms. The outcomes of IAA on plant root tissue are attention based and may be species specific. Responses to growing IAA concentrations strengthen from the stimulation of number one root tissue to the improvement of lateral and adventitious roots and eventually to the entire cessation of root increase (Patten, C. L., and B. R. Glick. 2002).

Indole acetic acid (IAA) is thought to stimulate each speedy responses (e.g. will increase in cellular elongation) and longtime responses (e.g.cellular department and differentiation) in flowers. L-tryptophan (L-Trp), is an amino acid, serves as a physiological precursor for biosynthesis of IAA in flowers and in microbes. Root exudates are herbal supply of L-Trp for rhizospheric microflora, which might also additionally decorate IAA biosynthesis in the rhizosphere. Microbial biosynthesis of IAA in soil is greater through L-Trp from root exudates or decaying cells. The reaction of cereals and greens to inoculation with a few PGPR micro organism has been attributed to the impact of plant growth regulators launched through these microorganisms (Flashman MA et al., 1996).

The present study concentrates on identity of IAA producing microorganism from agricultural land. The screening was done through TLC method. The highest IAA producer is identified by $16 \mathrm{~s}$ rRNA sequencing technique. Plant growth analysis was carried out to determine the efficacy of the IAA producer. 


\section{MATERIALS AND METHODS:}

\section{Sample series and isolation of Bacteria:}

Place serially diluted soil samples $(0.5 \mathrm{ml})$ on solidified nutrient agar medium, even as the use of spread plate and pour plate strategies to domesticate organisms from the samples. After all of the liquid in the medium has been absorbed, the petri dish is sealed and incubated in the dark at $37^{\circ} \mathrm{C}$ for twenty-four hours. Select colonies of various shapes and switch to nutrient agar medium. After numerous subcultures, natural isolates have been sooner or later received. Isolates examined in the microscope have been preserved in nutrient broth (NB) medium containing $15 \%$ glycerol at $-20^{\circ} \mathrm{C}$.

\section{Production of IAA and TLC Analysis:}

The decided on adverse bacterial lines had been cultured in $5 \mathrm{ml}$ nutrient broth medium in a test tube for24 hours. TLC slides have been organized with silica gel G and calcium carbonate.Propanol:Water (8:2) is used in the solvent system. Spot the extracted pattern and fashionable IAA $(10 \mathrm{mg} / 100 \mathrm{ml})$ at the TLC plate.

\section{DNA Isolation from Sample (Kit method):}

Add $750 \mu$ of homogeneous $1 \mathrm{X}$ Buffer to the tradition pellet, vortex and maintain in a $65^{\circ} \mathrm{C}$ dry bath for 20 mins, then upload $750 \mu 1$ of Lysis buffer and blend thoroughly. Then keep it in the dry water bath at $65^{\circ} \mathrm{C}$ and centrifuge at 12,000 rpm for 10 mins Transfer the supernatant to a $2 \mathrm{ml}$ check tube, upload an identical extent of isopropanol and blend it manually, switch to the column $(750 \mu 1$ every time) and spin at $12000 \mathrm{rpm}$ for 1 minute, upload $750 \mu 1$ wash buffer, then spin at 12000 rpm for 1 minute. Repeat the bathing buffer step, dry spin for two mins, upload $50 \mu \mathrm{l}$ of elution buffer, and spin at $12000 \mathrm{rpm}$ for 1 minute. The DNA consequently acquired ought to be quantified.

\section{DNA quantification:}

Estimate the DNA concentration by the means of recording the absorbance at 260 and $280 \mathrm{~nm}$ in a UV/VIS spectrophotometer. Collect $10 \mu \mathrm{l}$ of genomic DNA pattern in a quartz cuvette. Make a extent of $2 \mathrm{ml}$ with distilled water, measure the absorbance at 260 and $280 \mathrm{~nm}$ by the use of a UV spectrophotometer, calculate the ratio of A260/A280, and use the connection of 
double-stranded DNA (O.D) to calculate the DNA attention. At $260 \mathrm{~nm}=50 \mathrm{~g} / \mathrm{ml}$ PCR situations: Initial denaturation at $95^{\circ} \mathrm{C}$ for two mins; very last denaturation at $95^{\circ} \mathrm{C}$ for 30 seconds; annealing at $55^{\circ} \mathrm{C}$ for 30 seconds; elongation at $72^{\circ} \mathrm{C}$ for 1 minute; repeat steps 2 , 3 and 4 for 30 cycles. The last elongation is for 10 minutes at $72^{\circ} \mathrm{C}$ ant it is permanently stored in refrigerator at $4^{\circ} \mathrm{C}$.

\section{Preparation of PCR reaction mixture:}

Each PCR response used amplification performance of DNA barcode primers and carry out multiplex PCR evaluation consists of $1 \mu$ l DNA template (25 ng), $2 \mu \mathrm{l} 10 \mathrm{X}$ response buffer, $0.5 \mu \mathrm{l} \mathrm{MgCl} 2$ (50pM), $1 \mu \mathrm{l} \mathrm{dNTPs}$ blend (10mM), $1 \mu \mathrm{l}$ ahead primer (10pM), $1 \mu \mathrm{l}$ opposite primer (10pM), $0.5 \mu l$ Taq polymerase (five U/pi) volume $25 \mu l$ can be adjusted with molecular grade water. Primers are fashionable primers to be had for 16srRNA gene amplification. Gel purification protocol Cut the preferred DNA band at the gel, upload $600 \mu \mathrm{L}$ of gel dissolution buffer $55^{\circ} \mathrm{C}$ till the gel is absolutely dissolved. Add $200 \mu \mathrm{L}$ of isopropanol, blend and switch to the chromatographic column, spin 6at $12000 \mathrm{rpm}$ for 1 minute, upload $700 \mu \mathrm{L}$ washing buffer, spin at $12000 \mathrm{rpm}$ for 1 minute, and dry spin for two mins. Add $20 \mu \mathrm{L}$ of elution buffer and spin at 12000 rpm for 1 minute.

\section{Sanger Sequencing PCR:}

Initial denaturation at $95^{\circ} \mathrm{C}$ for 2 mins; very last denaturation at $95^{\circ} \mathrm{C}$ for 30 seconds; annealing at $50^{\circ} \mathrm{C}$ for 30 seconds; termination at $60^{\circ} \mathrm{C}$ for 4 mins; repeat steps 2,3 and 4 for 30 cycles. Always preserve it at $4^{\circ} \mathrm{C}$.

\section{Post Sequencing and PCR Purification:}

Add a 125mm $2.5 \mu \mathrm{L}$ EDTA to every properly and spin briefly. Use a multichannel pipette to upload $35 \mu \mathrm{L}$ of ethanol.Mix for 10 minutes at $2000 \mathrm{rpm}$ and centrifuge for 30 minutes at 3510 rpm.Use a tissue bed to decanter the ethanol at 300rpm (flip the plate over for 30 seconds).Add 40.Repeat the above referred to invert spin.Air dry for 30-45mins overlaying the plate with lint loose tissue. Add $13 \mu \mathrm{L}$ of $\mathrm{HiDi}$ Formamide short spin .Denature at $95^{\circ} \mathrm{C}$ for 5 mins.Place the plate in sequencer. 


\section{Data analysis:}

The received sequencing record might be in AB1 format, viewed through FinchTV, BioEdit, ChromasLite, SeqScanner and different software. The quality of the received series may be discovered via the peaks of the electropherogram. Use BLAST server or a server associated with a particular database to research sequencing data.

\section{Plant growth analysis:}

Take 4 pots of same length and quantity. Fill the pot with sterile soil and moisten it with sterile distilled water. Spinacia oleracea (pasalai keerai) seeds have been taken and sown in pots. Before sowing, sterilize the seeds with the running tap water, after which positioned them in a full of distilled water. A pinch of SDS was added and seeds have been shaken lightly for 1-2 min. The water was discarded and 70\% ethanol was added for 1-2 min. Ethanol become discarded and seeds have been positioned in the sterile distilled water,a pinch of $\mathrm{HgCl} 2$ was added to this and kept undisturbed for 15 minutes.Using distilled water, it is washed for another 3-4 times,all the water was discarded.After the surface is sterilized,the seeds are inoculated.The pots are marked according to way they are handled.The seedlings was gently removed after 10 days from the soil immersing the seedling in water to get rid of the soil. Evaluate the dry weight of the plant, shoot length and root length(cm).

\section{Shoot length and root length:}

Three plantlets have been randomly decided on to report the basis duration and shoot duration of the Spinacia oleracea (pasalai keerai) plant. They are measured through the use of a centimeter scale. Fresh weight (mg/g dry wt.) of three plant samples had been randomly decided with the experimental pot. They are divided into roots and shoots. Their dry weight is measured by means of the use of an electronic single scale.

\section{RESULTS:}

\section{Collection of soil and serial dilution:}

Soil samples have been accumulated from agricultural land, Coimbatore. The place surrounding the roots of the plant was collected and saved in a container. Figure- 1 indicates the 
sample collected place. Further the samples had been on nutrient agar. Different dilutions have been taken and plated. Figure-2shows the dilution from $10^{-2}$ to $10^{-7}$.

\section{TLC analysis and Fluorescence production analysis:}

Thin layer chromatography evaluation was done to identify the IAA producing microorganism.Four bacteria have been isolated from serial dilution which confirmed predominant growth on plates. All the 4 bacterial metabolites had been screened for IAA production. Sample-2 confirmed thick bands which verify the better IAA production (Figure-3). Therefore, bacterial sample-2 is chosen for further evaluation. From the fluorescence production, when seen under UV light the identified strain showed positive result(Figure-4).

\section{PCR amplification and species identification:}

From PCR amplification, the amplified product observed to be $850 \mathrm{bp}$. Figure-5 indicates the bands of agarose gel electrophoresis. Further the amplified 16s rRNA gene was subjected for sequencing. The identified sequence was shown below and the chromatogram was shown in Figure-6.

\section{Coding sequence:}

AGTTTGATCCTGGCTCAGATTGAACGCTGGCGGCAGGCCTAACACATGCAAGTCGA GCGGTAGAGAGAAGCTTGCTTCTCTTGAGAGAGGCGGACGGGTGAGTAAAGCCTAG GAATCTGCCTGGTAGTGGGGGATAACGTTCGGAAACGGACGCTAATACCGCATACG TCCTACGGGAGAAAGCAGGGGACCTTCGGGCCTTGCGCTATAGATGAGCCTAGGTC GGATTAGCTAGTTGGTGAGGTAATGGCTCACCAAGGCGACGATCCGTAACTGGTCTG AGAGGATGATCAGTCACACTGGAACTGAGACACGGTCCAGACTCCTACGGGAGGCA GCAGTGGGGAATATTGGACAATGGGCGAAAGCCTGATCCAGCCATGCCGCGTGTGG AACGTCAGTCGTAGCTAGCGTAAGCTGCCCGGTTAGCTGAGCTTGACGTCGACGCTG ACGTCGACGCTGACGCTAGCCGTACCGGTTAAGGCTTTAGCTGGACGTCGACCTGAC CGTAGCCGTAGCCAGTCGCGTAGCGTAGCGATGCCCGGTTAAAGGCTTCAAAACTG ACTGACTAGAGTATGGTAGAGGGTGGTGGAATTTCCTGTGTAGCGGTGAAATGGCA GATATAGGAAGGAACACCAGTGGCGAAGGCGACCACCTGGACTAATACTGACACTG AGGTGCGAAAGCGTGGGGAGCAAACAGGATTAGATACCCTGGTAGTCCACGCCGTA AACGATGTCAACTAGCCGTTGGGAGCCTTGAGCTCTTAGTGGCGCAGCTAACGCATT 
AAGTTGACCGCCTGGGGAGTACGGCCGCAAGGTTAAAACTCAAATGAATTGACGGG GGCCCGCACAAGCGGTGGAGCATGTGGTTTAATTCGAAGCAACGCGAAGAGCCTTA CCAGGCCTTGACATCCAATGAACTTTCTAGAGATAGATTGGTGCCTTCGGGAACATT GAGACAGGTGCTGCATGGCTGTCGTCAGCTCGTGTCGTGAGATGTTGGGTTAAGTCC CGTAACGAGCGCAACCCTTGTCCTTAGTTACCAGCACGTAATGGTGGGCACTCTAAG GAGACTGCCGGTGACAAACCGGAGGAAGGTGGGGATGACGTCAAGTCATCATGGCC CTTACGGCCTGGGCTACACACGTGCTACAATGGTCGGTACAGAGGGTTGCCAAGCC GCGAGGTGGAGCTAATCCCTCAAAACCGATCGTAGTCCGGATCGTAGTCTGCAACTC GACTGCGTGAAGTCGGAATCGCTAGTAATCGCGAATCAGAATGTCGCGGTGAATAC GTTCCCGGGCCTTGTACACACCGCCCGTCACACCATGGGAGTG GGTTGCACCAGAAGTAGC

\section{BLAST analysis:}

The similarity was determied among standard sequence and DNA base sequence with the help of BLAST method and the Query cover was displayed which shows the similarity percent of approximately $88 \%$ with Pseudomonas fluorescens. Since the similarity percent is low, high risk for the new strain.Figure-7and Figure-8 suggests the BLAST outcomes and BLAST graphic summary result.

\section{Pot assay:}

The Figure-9 shows plants with the aid of using pot assay approach. The seeds of Spinacia oleracea(pasalai keerai) have been grown on three exclusive pots with one pot which suggests the control,the any other pot handled with crude and the opposite with partly purified IAA. The table indicates the effects of shoot length,root length and fresh weight of the vegetation. From the Table-2,it showsthe outcomes received, the plant handled with the partially purified IAA suggests the more growth in all factors,than evaluating with crude and water.

\section{DISCUSSION:}

Indole acetic acid (IAA) manufacturing is a major property of soil micro organism specifically Pseudomonas and Bacillus. The present work deals with indole acetic acid generating micro organism from the soil of various district of Uttar Pradesh. Optimization of indole acetic acid production was done at unique cultural conditions of $\mathrm{pH}$ and temperature with 
various media additives including carbon and nitrogen supply, tryptophan attention (Shih-Yung ,2010).

Indole-3-acetic acid (IAA) is the maximum studied auxin in plant life, and its biosynthesis pathway has been investigated for over 70 years. Although the entire picture of auxin biosynthesis stays to be elucidated, remarkable development has been made these days in umderstanding the mechanism of IAA biosynthesis. Genetic and biochemical research show that IAA is specially synthesized from L-tryptophan (Trp) through indole-3-pyruvate by means of two-step reactions in Arabidopsis. While IAA is likewise made from Trp through indole3acetaldoxime in Arabidopsis, this pathway likely performs an auxiliary position in plant life of the own circle of relatives Brassicaceae. Recent research recommend that the Trp-independent pathway isn't always a chief path for IAA biosynthesis, however they monitor an essential position for a cytosolic indole synthase on this pathway( Pollmann, Neu, Weiler,2003).

IAA generating microorganism from rhizosphere soil and their impact on seed germination changed into investigated by means of Sharnali Das et al. Out of 30 isolates, eight (viz. Aux four, Aux 9, Aux14, Aux16, Aux 19, Aux 20, Aux 21 and Aux 25) have been able to produce IAA which was confirmed by Salkowski reagent test.Isolates had been characterised on the basis of visible observations, gram staining and bio chemical assessments together with oxidase, catalase, indole, TSI, methyl red, Voges-Proskauer, citrate utilization, urease and starch hydrolysis test.The IAA producing bacteria are rod and spherical formed gram Positive and gram negatIvemicroorganism. IAA has been implicated in really all elements of plant growth and improvement inclusive of the developing of longer roots with elevated variety of root hairs and root laterals that are concerned in the nutrient uptake (Datta and Basu, 2000). Furthermore, it complements embibal activity, inhibit or delay abscission of leaves and promote flowering and fruiting in plant (Zhao, 2010).

This study suggests that the Spinacia oleracea (pasalai keerai) seeds have been sown in 3 pots (pot assay).The seeds that have been dealt with partially purified IAA confirmed larger growth of shoot length,root length and fresh weight than the seeds dealt with crude and water (control). Dobbelaere etal (2003) and Cakmak1 (2005a) were reported that PGPR can increase yield and leaf area index, shoot and root weight and delay leaf senescence.Numerous different research have proven a huge increase in dry matter accumulation and seed yield while inoculated 
with PGPR (Perveen et al., 2002; Waniet al., 2007; Mishra et al., 2010; Sharifiet al., 2011). Dilfuza (2007) stated that once corn seeds are inoculated with Azospirillum brazilance indicates elevated dry matter accumulation. Mishra et al., (2010) said that the maximum of diagnosed isolates shows significant increase of each shoot and root of Cicerarietinum seedlings.

The outcomes of the study by Sharifiet al., (2011) confirmed that the seeds inoculating with Plant Growth Promoting Rhizobacteria confirmed grain yield, plant height, quantity of kernel in keeping with ear, variety of grains according to ear row significantly. Strains of Pseudomonas putida and Pseudomonas fluorescens increases root and shoot elongation in canola (Glick et al., 1997).Pseudomonas and Bacillus micro organism posses numerous plant growth promoting activity. Compare to those microorganism, Pseudomonas fluorescence have ability to supply excessive quantity of IAA manufacturing than Bacillus subtilis and control. The end result shows that those isolates consists of PGP activities, that percent of IAA manufacturing of those bacterial activities are numerous greatly. Mahalakshmi and Reetha (2009), (Saitou N and Nei M 1987) said identical consequences in checking out PGP activities of bacteria which are collected from the rhizosphere of tomato.

The rhizosphere microorganism specifically Pseudomonas fluorescens, have extra capacity to grow the host plant through numerous mechanism to decrease the plant illnesses which incorporates manufacturing of effective siderophores (O sullivan and O Gara 1992): Has and Defago 2005). These likePseudomonas fluorescens and different microorganism Bacillus subtilis had been in addition studied or their impact on plant growth under controlled situations.Data received from the pot experiments established tremendous effects on root elongation of handled plant life over the control. This shows that those micro organism have the performance to enhance the size of roots and shoots of the plant and those may be taken into consideration as plant growth promoters.

\section{CONCLUSION:}

Out of four organisms isolated from serial dilution, Sample-2 confirmed thick bands of IAA production by TLC analysis. 16s rRNA analysis showed the isolated organism was found to be Pseudomonas fluorescence with similarity of $88 \%$. The isolated organism treat plants showed increased shoot and root length in plant growth analysis. In conclusion the isolated IAA producing bacteria can be used as efficient biofertilizer inoculants to promote plant growth. 


\section{REFERENCES:}

Arshad, M., Frankenberger, W.T. Jr. Microbial production of plant growth regulators. In: Metting FB Jr(eds). Soil Microbial Ecol, Marcel Dekker Inc., New York. pp: 307-347(1992)

Datta C. and Basu P. Indole acetic acid production by a Rhizobium species from root nodules of a leguminous shrub Cajanus cajan, Microbiol Res.155: 123(2000)

Dobbelaere S, Vanderleyden J, Yaacov Y, Okon L . Plant growth-promoting effects of diazotrophs in the rhizosphere. Critical Rev. Plant Sci. 22: 107-149(2003)

Glick B.R., The enhancement of plant growth by free-living bacteria. Canadian Journal of Microbiology 41: 109-117.(1995)

Ibiene AA, Agogbua JU, Okonko IO and Nwachi GN. Plant growth promoting rhizobacteria (PGPR) as biofertilizer: Effect on growth of Lycopersicum esculentus. Journal of American Science8(2):318-324(2012).

MacFaddin, J.F. Biochemical tests for identification of medical bacteria. Williams and Wilkins, London. (2000)

Mahalakshmi S \& Reetha D. Rec Res in Sci and Technol, 1(1):26-29(2009)

O Sullivan DJ, O Gara F , Traits of fluorescent Pseudomonas spp. Involved in suppression of plant root pathogens. Microbiol. Rev. 56:662-676(1992)

Patten C, Glick B , Role of Pseudomonas putida indole acetic acid in development of the host plant root system. Appl. Environ. Microbiol. 68:3795-3801(2002)

Perveen S, Khan MS, Zaidi A . Effect of rhizospheric microorganisms on growth and yield of greengram (Phaseolus radiatus L.). Ind. J. Agric. Sci. 72: 421-423(2002)

Shahab S, Ahmed N. Effect of various parameters on the efficiency of zinc phosphate solubilization by indigenous bacterial isolates . Afr. J. Biotechnol. 7 (10): 1543-1549(2008).

Sadaf Shahab, Nuzhat Ahmed and Nasreen S. Khan .Centre for Molecular Genetics, University of Karachi, 75270, Pakistan,(2009) 
Sharnali Das, Tauhidur Rahman Nurunnabi, Rehana Parveen, Amatun Nur Mou,Md. Emdadul Islam, Kazi Mohammad Didarul Islam and S.M. Mahbubur Rahman,International Journal of Current Microbiology and Applied Sciences,ISSN: 2319-7706 Volume 8 Number 03 (2019)

Shih-Yung, H. 2010. IAA production by Streptomyces scabies and its role in plant microbe interaction. Msc thesis, Cornell University.

Sturz, A. V., and Christie, B. R.Beneficial microbial allelopathies in the root zone: the management of soil quality and plant disease with rhizobacteria. Soil and Tillage Research. 72(2): 107-123(2003).

Subba Rao, NS, Soil Microbiology (Fourth Edition of Soil Microorganisms and Plant Growth) Science Publishers, Inc. USA.(1999)

Verma, J.P., J. Yadav, K.N. Tiwari and V. Singh. Impact of plant growt promoting rhizobacteria on crop production. Int. J. Agric. Res., 5: 954-983.(2010)

Wu, S.C., Z.H. Cao., Z.G. Li., K.C. Cheung and M.H. Wong. Effects of biofertilizer containing $\mathrm{N}$-fixer, $\mathrm{P}$ and $\mathrm{K}$ solubilizers and AM fungi on maize growth: a greenhouse trial. Geoderma. 125:155-166.(2005)

Zhao,Y.Auxin biosynthesis and its role in plant development. Annual review of plant biology. 61: 49-64.(2010) 
Table 1: PCR reaction mixture

\begin{tabular}{|c|c|c|}
\hline SI.No & COMPONENTS & CONCENTRATIONS \\
\hline 1 & Forward primer (27F) & $10 \mathrm{pM}$ \\
\hline 2 & Reverse primer (1492R) & $10 \mathrm{pM}$ \\
\hline 3 & $10 \mathrm{Mm}$ dNTPs & $10 \mu \mathrm{M}$ \\
\hline 4 & $10 \mathrm{X}$ PCR Buffer & $2 \mathrm{x}$ \\
\hline 5 & $25 \mathrm{Mm} \mathrm{Mgcl}{ }_{2}$ & $25-40 \mathrm{ng}$ \\
\hline 6 & Template DNA & $5 \mathrm{U}$ \\
\hline 7 & Taq polymerase & Make up to $25 \mu \mathrm{l}$ \\
\hline 8 & Nuclease free water & \\
\hline
\end{tabular}

Table 2: Pot assay

\begin{tabular}{|c|c|c|c|}
\hline S.NO & Shoot length (mm) & Root length (mm) & Fresh weight (g) \\
\hline Control & 8 & 10 & 0.030 \\
\hline Crude & 12 & 11 & 0.045 \\
\hline Partial purified & 22 & 18 & 0.08 \\
\hline
\end{tabular}




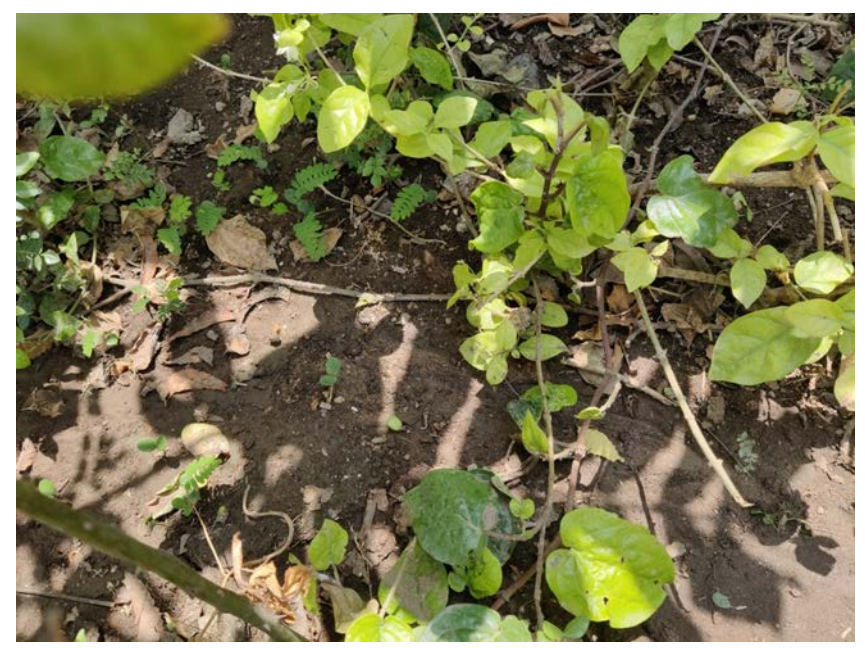

Figure-1: Collection of soil sample

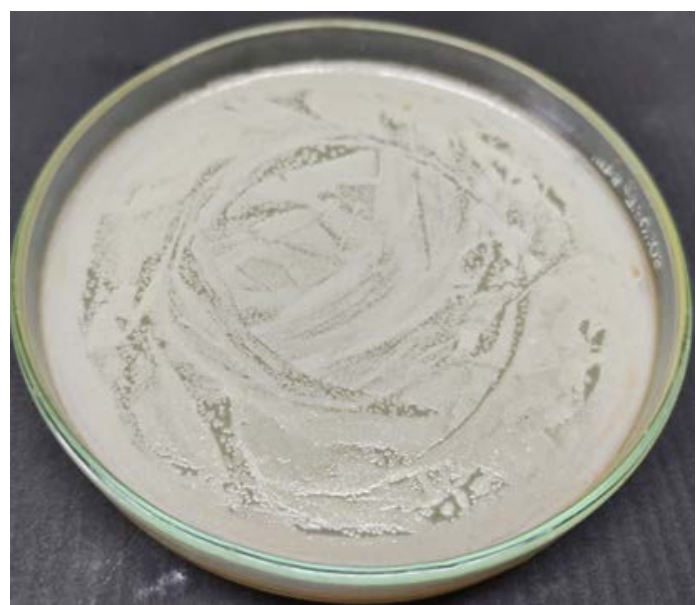

$10^{-2}$ dilution

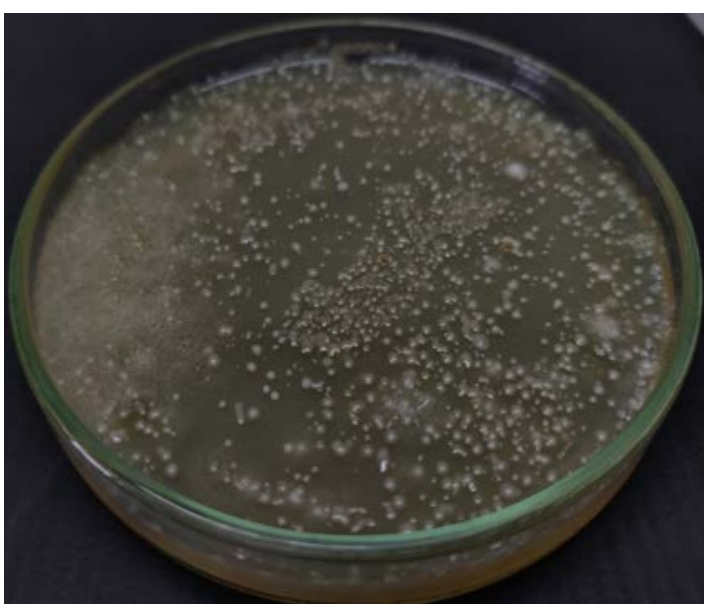

$10^{-5}$ dilution

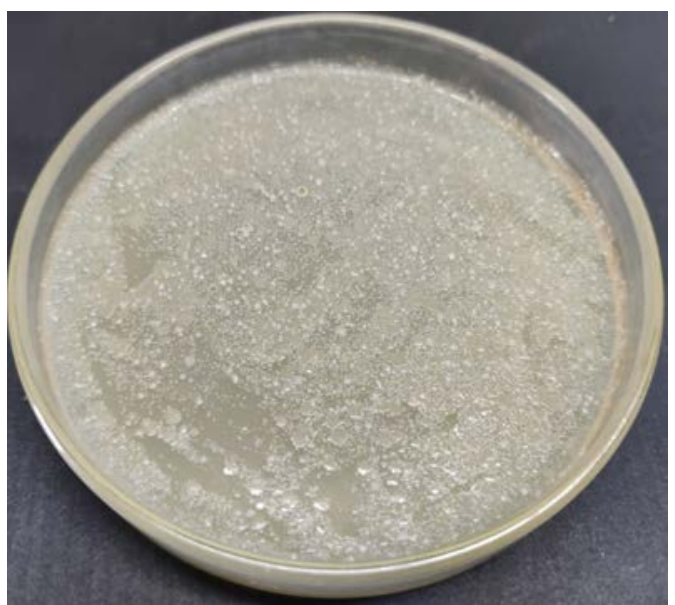

$10^{-4}$ dilution

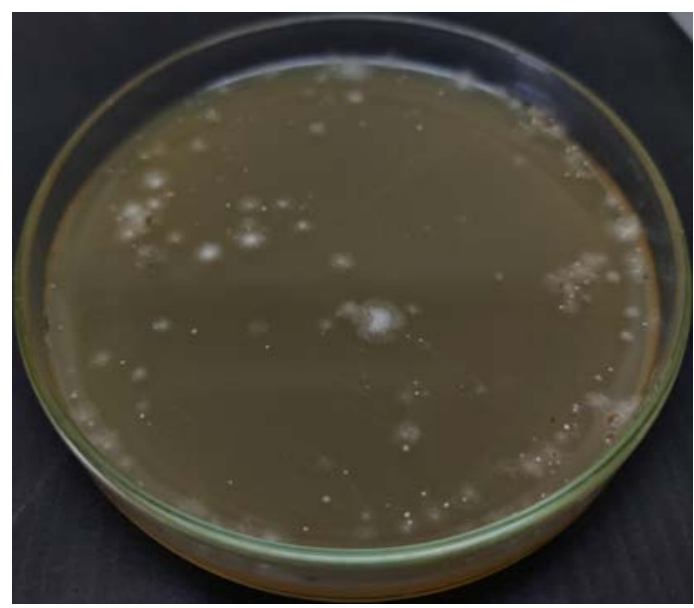

$10^{-7}$ dilution

Figure-2:Serial dilution of soil samples 


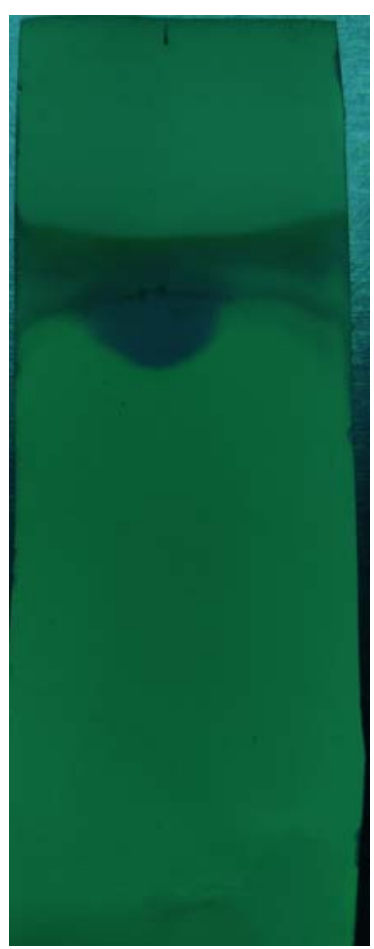

Strain-1

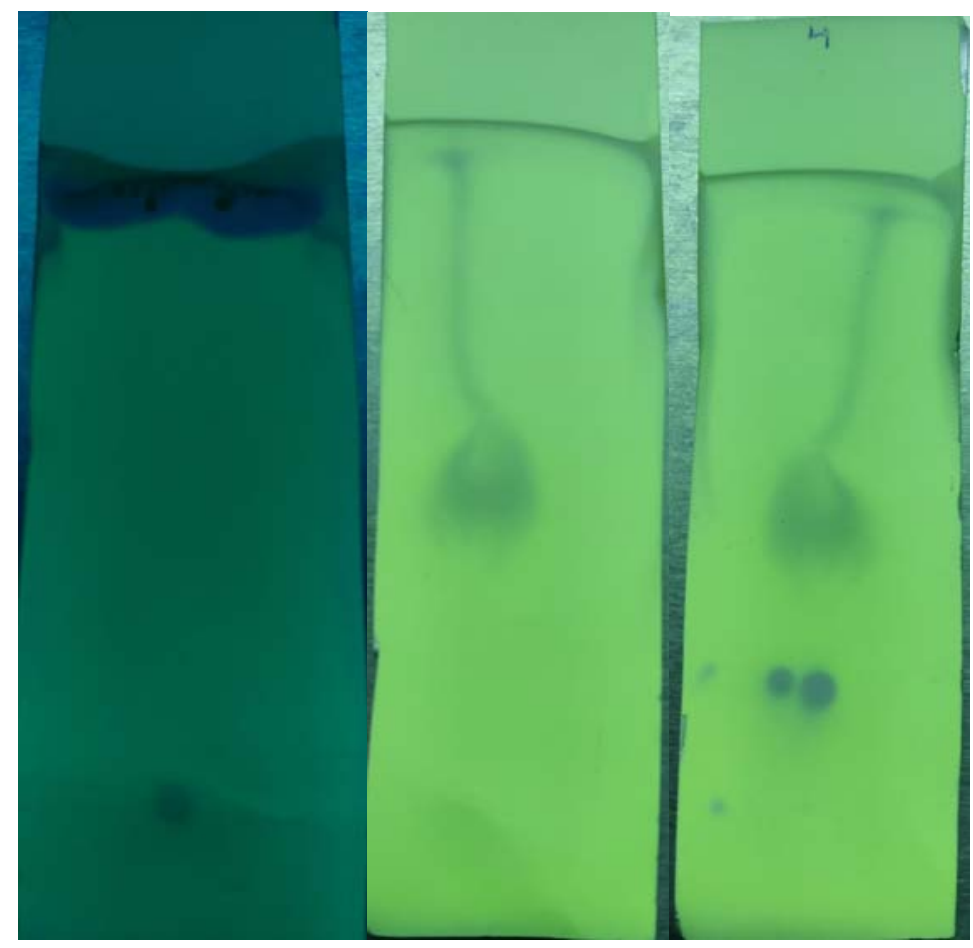

Strain-3

Strain-4

Figure-3: Thin layer chromatographic analysis of isolated bacteria

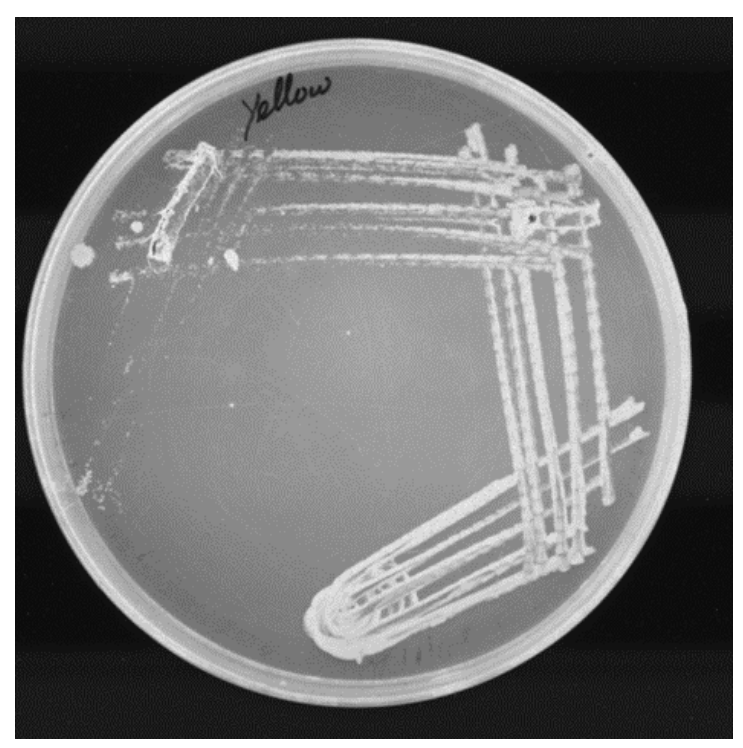

Figure-4: Fluorescence production analysis 


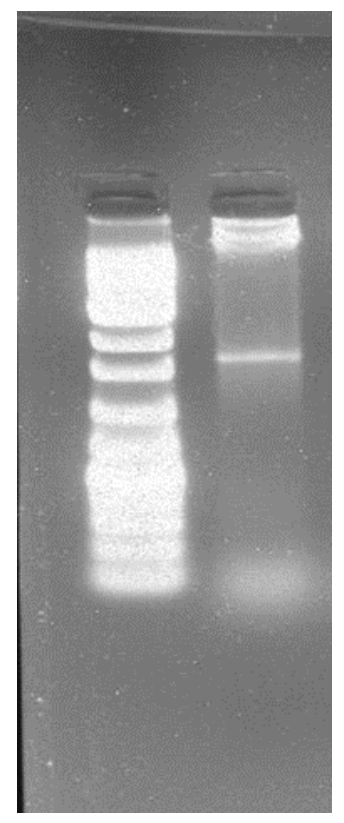

\section{S}

1) M- DNA Ladder(100-10,000bp),

2) S- Bacterial amplified PCR product (850bp)

Figure-5:PCR amplified 16s r RNA

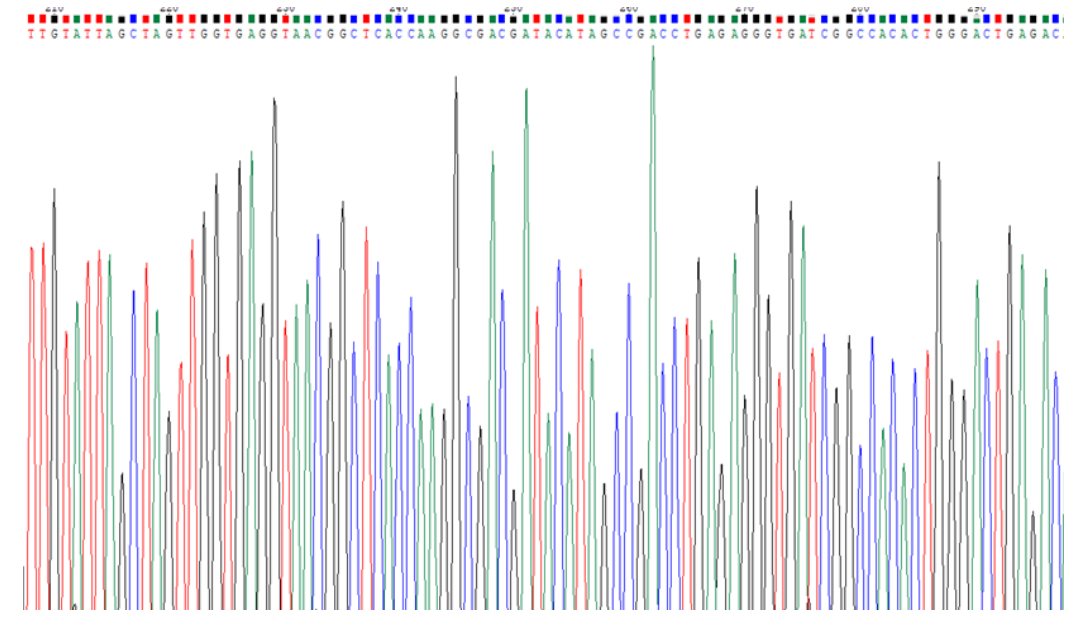

Figure-6: Chromatogram of the sequence 


\begin{tabular}{|c|c|}
\hline Job Title & Nucleotide Sequence \\
\hline RID & $\underline{68 F Z 3 S F B 013}$ Search expires on 04-01 17:24 pm Download All $\vee$ \\
\hline Program & BLASTN 2 Citation ${ }^{\vee}$ \\
\hline Database & nt $\underline{\text { See details }}{ }^{v}$ \\
\hline Query ID & Ic||Query_44795 \\
\hline Description & None \\
\hline Molecule type & dna \\
\hline Query Length & 1459 \\
\hline Other reports & Distance tree of results MSA viewer $\mathbf{0}$ \\
\hline
\end{tabular}

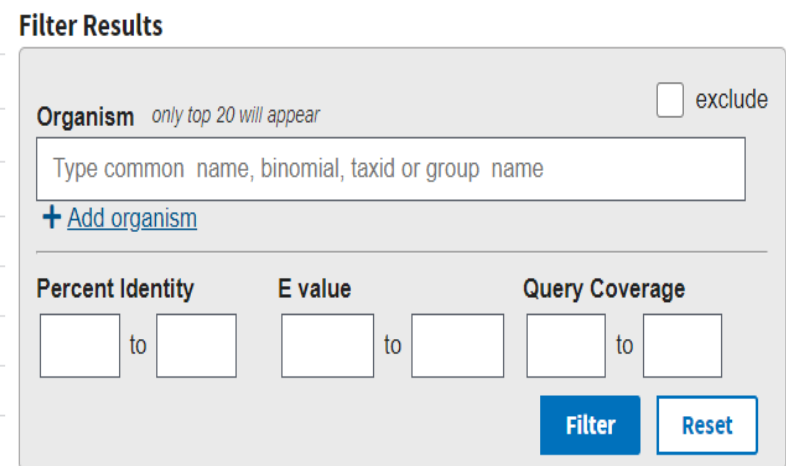

\begin{tabular}{|c|c|c|c|c|c|c|c|c|c|c|c|}
\hline \multicolumn{2}{|c|}{ Descriptions } & Graphic Summary & Alignments & Taxonomy & & & & & & & \\
\hline \multicolumn{5}{|c|}{ Sequences producing significant alignments } & Download $\vee$ & New Se & Select columns & $\checkmark$ Sho & now $\lcm{1}$ & $100 \mathrm{~V}$ & $\boldsymbol{3}$ \\
\hline \multicolumn{5}{|c|}{ velect all 100 sequences selected } & GenBank & Graphics & \multicolumn{3}{|c|}{ Distance tree of results } & \multicolumn{2}{|c|}{ NewMSA Viewer } \\
\hline & & & Description & & Scientific Name & & Common Name & $\stackrel{\text { Taxid }}{\vee}$ & $\begin{array}{l}\text { Max } \\
\text { Score } \\
\nabla\end{array}$ & $\begin{array}{l}\text { Total } \\
\text { Score } \\
\nabla\end{array}$ & $\begin{array}{l}\text { Query } \\
\text { Cover } \\
\nabla\end{array}$ \\
\hline \multicolumn{5}{|c|}{ Pseudomonas sp. strain ME2020 $16 S$ ribosomal RNA gene, partial sequence } & $\underline{\text { Pseudomonas sp. }}$ & & NA & $\underline{306}$ & 1668 & 2388 & $88 \%$ \\
\hline \multicolumn{5}{|c|}{ D Psendomon } & Pseuddmannas fluoresscens & & NA & 294 & 1668 & 2351 & $87 \%$ \\
\hline
\end{tabular}

Figure-7:BLAST results

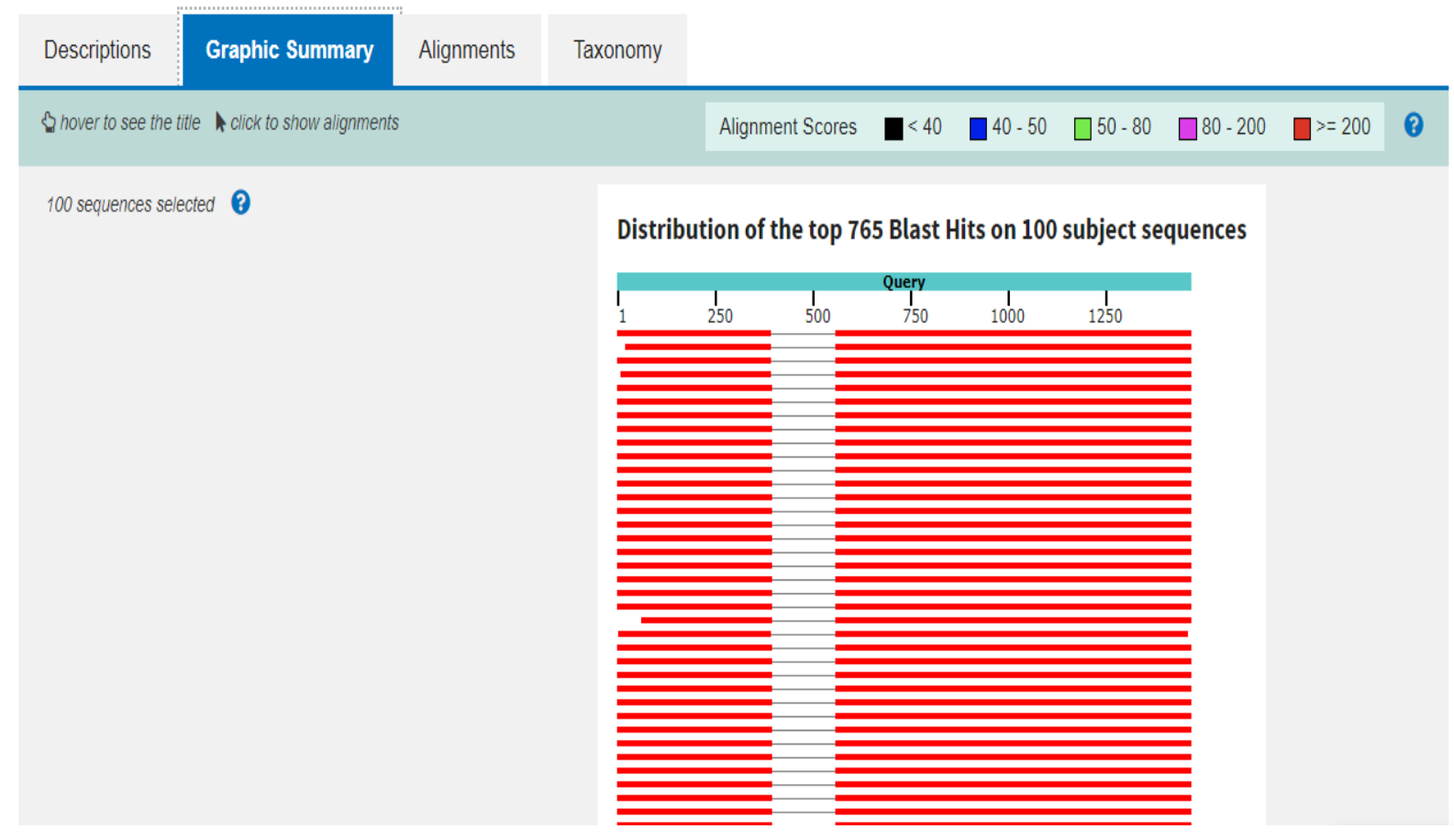

Figure-8:BLAST graphic summary result 

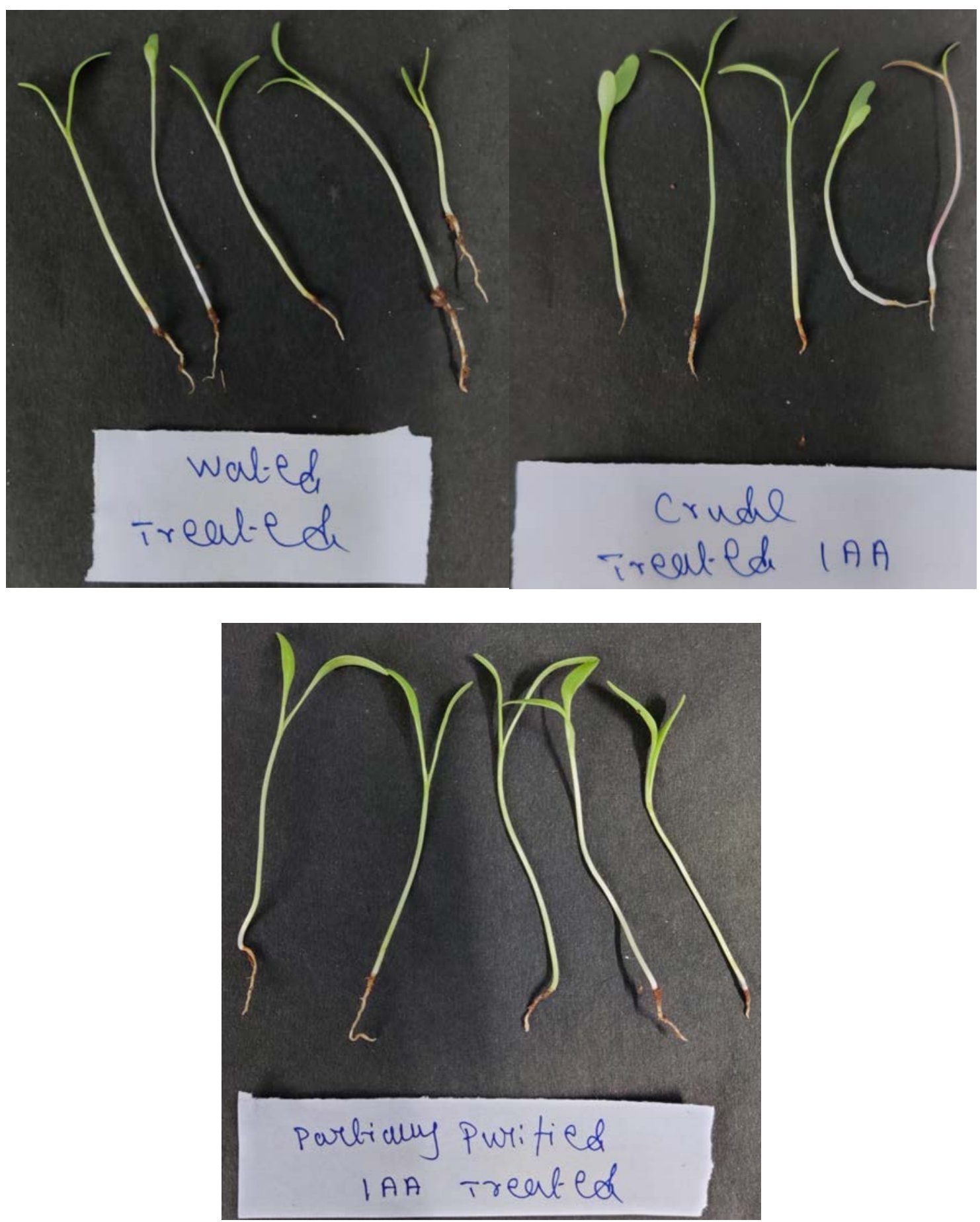

Figure-9:Pot assay 